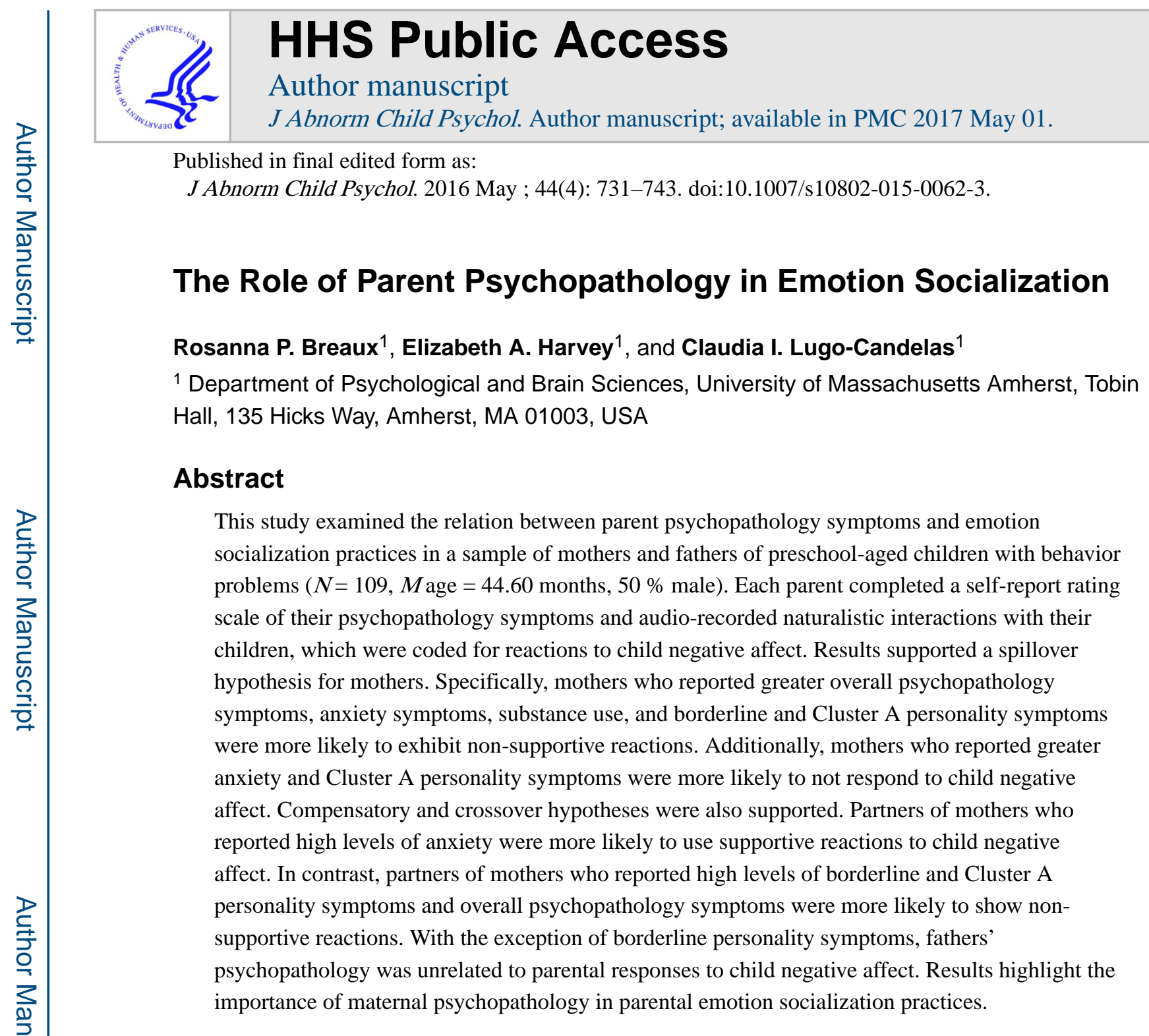

\title{
Keywords
}

Emotion socialization; Parent psychopathology; Preschoolers; Family system

Parents are thought to play a critical role in children's emotional development (Cole et al. 2009; Denham et al. 2007) through the process of emotion socialization (Denham and Kochanoff 2002; Hersh and Hussong 2009; Morris et al. 2007; Warren and Stifter 2008). However, little is known about the determinants of parents' emotion socialization practices (Denham et al. 2007). Understanding factors that contribute to emotion socialization may provide important insights into how to help parents engage in more effective practices. Parent psychopathology symptoms have been widely linked with parenting practices (see Zahn-Waxler et al. 2002, for a review) and are thought to be one of the most important predictors of maladaptive parenting (Belsky 1984; Dix and Meunier 2009). However, the role that parental psychopathology symptoms may play in parents' emotion socialization

Elizabeth A. Harvey eharvey@ psych.umass.edu.

Conflicts of Interest The authors have no competing or potential conflicts of interest. 
practices remains unclear. Moreover, children with behavior problems have particular difficulty with emotion regulation (e.g., Cole et al. 1994), so it is critical to understand factors that contribute to the ways that parents help children with behavior problems regulate their emotions. This study sought to address this gap in the literature by examining the relation between parent psychopathology symptoms and emotion socialization practices among parents of preschool children with behavior problems.

\section{Emotion Socialization}

The Emotion Socialization Antecedents and Mechanisms model is a heuristic model that specifies three main parental emotion-related socialization behaviors that help guide children's emotion regulation: (a) parental expressivity of emotions, (b) parental discussion of emotion, and (c) parental reaction to children's emotion (Eisenberg et al. 1998). Each of these aspects has been linked with children's emotional and social functioning. In particular, children demonstrate greater emotion competence when their parents express more positive affect (e.g., Michalik et al. 2007), discuss emotions more (e.g., Eisenberg et al. 1998), use more supportive reactions to children's negative affect (e.g., provide support or comfort, help problem-solve; Denham et al. 2007), and use fewer non-supportive reactions to negative emotions (e.g., are punitive or dismissing; McElwain et al. 2007). Although much of this literature has focused on typically developing children, there is evidence that emotion socialization practices may be particularly important for children with behavior problems. For example, Denham et al. (2000) found that maternal anger expression more strongly predicted later externalizing problems among children with initially high levels of behavior problems than among children with initially low levels of behavior problems.

Given the importance of emotion socialization practices for children's development, it is critical to identify factors that interfere with parents' use of effective emotion socialization practices. The present study focuses on predictors of parental reactions to children's negative emotions. This dimension of emotion socialization is critical to children's emotional development, but its determinants are poorly understood. Furthermore, research on the determinants of parental reactions to children's negative emotions has largely relied on selfreport measures (e.g., Fabes et al. 1990; Friedlmeier et al. 2011; Raval and Martini 2009), which are subjective and may be influenced by social desirability. Thus, it is important to explore parental responses to negative affect during naturalistic parent-child interactions.

\section{Parent Psychopathology Symptoms and Parenting}

Theoretical models highlight the importance of parent psychopathology symptoms as a determinant of maladaptive parenting practices (Belsky 1984; Dix and Meunier 2009), and there is a large empirical literature linking parent psychopathology symptoms and maladaptive parenting practices (see Zahn-Waxler et al. 2002, for a review). Researchers have sought to understand the mechanisms through which parental psychopathology can disrupt parenting. For example, Dix and Meunier (2009) have proposed an action-control framework that posits that parental depression may impair parenting through cognitive, affective, and motivational processes. In particular, depression may lead parents to prioritize parent-centered goals over child-oriented goals and to have more negative appraisal of 
children, lower feelings of parenting competence, less expression of positive emotion and greater expression of negative emotion toward children, and impaired ability to select appropriate parenting practices.

Although parental depression has been most widely studied in the literature on parent psychopathology and parenting (e.g., Lovejoy et al. 2000), other forms of psychopathology have also been linked to disruptions in parenting. For example, anxiety symptoms (e.g., Woodruff-Borden et al. 2002), substance use (e.g., Edwards et al. 2009), and personality disorder symptoms (e.g., Johnson et al. 2006b) have all been linked to impairment across a variety of parenting practices. It is unclear whether the disproportionate focus on parental depression is because depression disrupts parenting more than other forms of psychopathology. Relatively few studies have examined multiple forms of psychopathology within the same study, making it difficult to evaluate the differential impact of various types of psychopathology on parenting. These few studies suggest that anxiety, substance abuse, and personality disorder symptoms show relations with maladaptive parenting that are similar in magnitude to relations between depression and parenting (Harvey et al. 2011; Johnson et al. 2004; Johnson et al. 2006a, b). More research is needed to build on these studies to examine whether different types of psychopathology exert different influences on parenting, particularly in the area of emotion socialization.

Different forms of psychopathology may have different effects on parenting for several reasons. Factor analyses have consistently reproduced multiple dimensions of psychopathology (e.g., Achenbach et al. 1989; Achenbach and Edelbrock 1978; Markon 2010) in both children and adults. These studies suggest that although different types of psychopathology are comorbid and share certain impairments, they each also display their own unique symptom patterns. These unique symptom profiles of different forms of psychopathology may impact parenting in different ways. For example, forms of psychopathology that are characterized by avoidance (e.g., anxiety, avoidant or schizoid personality) may result in avoidant parenting practices, whereas forms of psychopathology that involve affect instability (e.g., bipolar, borderline personality) may result in intrusive parenting practices. However, there are also a number of reasons why different forms of psychopathology might have similar effects on parenting. First, research suggests that a unidimensional psychopathology construct may underlie psychiatric disorders (Caspi et al. 2014; Lahey et al. 2012), and provide a more parsimonious conceptualization than the current classification of distinct diagnoses. This may explain high rates of comorbidity among types of psychopathology, with almost half of individuals who meet criteria for one disorder having another comorbid disorder (Newman et al. 1998; Kessler et al. 2005). Second, transdiagnostic features such as latent liability (Krueger and Markon 2006) and emotion dysregulation (Barlow 2000; Kring and Werner 2004) are characteristic of most forms of psychopathology and may play a key role in disruptions in parenting. Third, perhaps because of these transdiagnostic similarities, the mechanisms that have been theorized to underlie the effects of parental depression on parenting are likely to also be relevant for other forms of psychopathology. For example, parental anxiety, substance abuse, and personality disorder symptoms are likely to impact parenting through the same cognitive, affective, and motivational processes that Dix and Meunier (2009) have proposed in their action-control framework of parental depression. That is, these symptoms are also 
likely to affect parental goals (e.g., prioritizing parent goals over child goals), emotion expression (greater expression of negative affect), and responses (ability to select and implement appropriate parenting practices). Thus, there are theoretical reasons why one might expect both similar and different effects of different types of psychopathology, so empirical research is needed to determine which in fact is the case.

Although there is a large literature on the relation between parent psychopathology symptoms and parenting, it has largely focused on only one aspect of emotion socialization: parental emotion expression. The disruptive effects of parent psychopathology symptoms on parental expression of emotions have been central to theoretical models of the effects of parent psychopathology on parenting (Dix and Meunier 2009), and have been welldocumented in empirical studies. For example, parental depression (e.g., Zahn-Waxler et al. 2002), anxiety (e.g., Whaley et al. 1999; Johnson et al. 2006b), and personality disorders (Johnson et al. 2006b) have been linked to greater parental expression of negative affect and/or less expression of warmth/positive affect. In a previous study using the same dataset as the current study, parent psychopathology symptoms were found to be an important determinant of parental warmth and overreactivity/negative affect among parents of children with behavior problem (Harvey et al. 2011). However, there is scant research examining the link between parent psychopathology symptoms and parents' reactions to child negative affect, a key dimension of emotion socialization. Nelson et al. (2009) found that parental depressive symptoms were not significantly related to their own supportive reactions to child negative affect. Additionally, family chaos, which has been linked with parent psychopathology symptoms (e.g., Hussong et al. 2008; Mokrova et al. 2010), has been associated with less supportive reactions to children's negative affect (Valiente et al. 2007), which provides indirect support for the notion that parent psychopathology symptoms may be linked with parental reactions to child negative affect. Research is needed to build on this very small body of research, and there is a particular need for observational studies to examine the link between parent psychopathology symptoms and parents' reactions to child negative affect. Additionally, as parents of children with disruptive behaviors are known to have higher rates of psychopathology (e.g., Middleton et al. 2009; Pfiffner et al. 2005; Takeda et al. 2010), examining this relation in a sample of children with behavior problems is particularly important.

\section{Spillover, Crossover, and Compensatory Processes}

Family scholars have long recognized that difficulties experienced by an individual in one domain can transfer through both intraindividual and interindividual processes to other subsystems within the family (e.g., Crouter et al. 2001; Roberts and Levenson 2001; Westman 2001). For example, it has been postulated that sources of family stress, including parent psychopathology symptoms, may affect emotion socialization through spillover, crossover, and compensatory processes (Nelson et al. 2009). Spillover effects involve intraindividual transfer of emotional functioning from one domain within an individual to another domain involving the individual. Thus, parents' psychopathology symptoms are likely to affect their own reactions to child negative affect and this may occur through a variety of processes. Because parents with psychopathology may experience significant emotion regulation problems (e.g., Gross and Levenson 1997), they may be particularly 
vulnerable to the effects of child negative affect on their own emotions, which in turn are likely to interfere with their ability to communicate effectively with their children during episodes of negative affect (Cummings and Davies 1994). Furthermore, in an effort to reduce their own distress, parents with psychopathology symptoms may prioritize parentcentered rather than child-centered goals (Dix and Meunier 2009), which may lead to the use of less supportive reactions to child negative affect. In addition, symptoms of parent psychopathology may bias parents' appraisals, resulting in more negative attributions for child behavior (Dix and Meunier 2009), which also may interfere with supportive emotion socialization practices. Crossover effects involve interindividual effects of one individual's emotional functioning on another subsystem within the family. In particular, parents' psychopathology symptoms may not only affect their own interactions with their children, but may also interfere with their partners' reactions to child negative affect, by placing strain on the partner. Finally, compensatory effects also involve interindividual effects of emotional functioning on another family subsystem, but in the opposite direction than crossover effects. Partners may compensate for a parent's psychopathology and possibly impaired parenting by using more supportive emotion socialization practices.

There is widespread support for spillover effects of psychopathology on parent-child interactions including evidence of spillover effects on parental emotion expression with their children (e.g., Eiden et al. 2007; Jacob and Johnson 1997; Lovejoy et al. 2000). However, very few studies have examined spillover effects on other key aspects of emotion socialization, including parental reactions to child negative affect. Research on the partner effects of parent psychopathology symptoms on parenting has been mixed with some evidence of crossover effects and some for compensatory effects. Studies of substance abuse and parenting have generally supported crossover effects. In clinical samples, substance abuse in one parent has been related to disruptions in partners' parenting (e.g., Capaldi et al. 2008; Edwards et al. 2009; Eiden et al. 2007), although compensatory effects have been observed in parents of children with behavior problems (Harvey et al. 2011). Results have been inconsistent for parent depression, with some finding husbands of depressed mothers to be more engaged (e.g., Hops et al. 1987), others finding husbands' parenting to be more disrupted (e.g., Goodman 2008), and others finding neither crossover nor compensatory effects (Harvey et al. 2011). Examination of mothers' and fathers' personality disorder and anxiety symptoms has provided evidence for compensatory effects on parenting (Harvey et al. 2011). To our knowledge, the only study that has examined crossover and compensatory effects on parental reactions to negative affect (Nelson et al. 2009) found evidence for the compensatory hypothesis for parental depression symptoms and supportive reactions. Thus, there is a need to build an empirical knowledge base on the spillover, crossover, and compensatory effects of different dimensions of parent psychopathology symptoms on parental reactions to child negative affect.

\section{The Present Study}

This study sought to address these gaps in the literature by examining relations between parents' self-reported psychopathology symptoms and observed parental reactions to child negative emotion in a sample of preschool children with behavior problems. In particular, this study examined whether patterns of relations were consistent with spillover, crossover, 
and compensatory effects on parenting. Although much of the literature on parent psychopathology symptoms and parenting has examined maternal depression, there is evidence that other dimensions of parent psychopathology (e.g., Chilcoat et al. 1996; Riordan et al. 1999), including fathers' psychopathology (e.g., Das Eiden and Leonard 2000), may spillover into their parenting. Additionally, more research is needed to better understand the potential crossover and compensatory effects of parent psychopathology symptoms on partners' emotion socialization practices. Therefore, the present study focused on a broad array of dimensions of parent psychopathology symptoms in both mothers and fathers, and addressed both parents' own and their partners' emotion socialization practices. This study examined preschool-aged children, because this is thought to be a critical developmental period for emotional development (Denham 1998). Moreover, we focused on young children with behavior problems, because these children are at risk for a host of negative outcomes (Campbell 1994; DuPaul et al. 2001), and are likely particularly vulnerable to the effects of poor emotion socialization practices. The findings of this study may be useful in informing the development of emotion socialization interventions for atrisk children and in better understanding the role of parent psychopathology symptoms in family processes. The present study examined the following questions:

1) Spillover hypothesis: Are parent psychopathology symptoms associated with parents' own reactions to child negative affect?

Although the mechanisms that account for the relations between psychopathology and emotion socialization practices are likely to vary somewhat across specific dimensions of psychopathology, there are a number of processes that are likely shared. For example, most dimensions of psychopathology involve symptoms of emotion dysregulation, which may make parents vulnerable to the effects of child negative affect, resulting in interference with their ability to provide supportive reactions to child negative emotion. Moreover, although each type of psychopathology may have mechanisms that are unique, resulting in different pathways to impairment in emotion socialization, the resulting degree and type of impairment may be similar. Therefore, it was predicted that parents with more symptoms of anxiety, depression, personality disorders, and substance use would use more non-supportive and non-response reactions and fewer supportive reactions to child negative affect.

2) Crossover and compensatory hypotheses: Are parent psychopathology symptoms associated with their partners' emotion socialization practices?

Given evidence that parent psychopathology symptoms are related to partners' parenting in general (e.g., Capaldi et al. 2008; Edwards et al. 2009; Goodman 2008; Hops et al. 1987), it was predicted that parental symptoms of anxiety, depression, personality disorder, and substance use would be associated with partners' responses to children's negative emotions. However, because there is evidence both that parent psychopathology symptoms can crossover and disrupt partners' parenting (e.g., Goodman 2008), and that parents compensate for their partners' psychopathology symptoms by using more effective practices (e.g., Harvey et al. 2011; Hops et al. 1987), no predictions were made regarding the direction of these relations. 


\section{Method}

\section{Participants}

Participants were drawn from a sample of 199 children with behavior problems and their parents who took part in a longitudinal study aimed at understanding the early development of attention-deficit/hyperactivity disorder and oppositional defiant disorder among preschoolers (Harvey et al. 2009). A subset of children $(N=109)$ who met the following criteria were the focus of the present study: (a) at least one parent completed an audiotaped parent-child interaction and (b) both the mother and father completed a measure of parent psychopathology symptoms. Children ( 55 boys and 54 girls) were all 3 years old at the time of the initial screening and were 36.43 to 50.00 months ( $M=44.60$ months, $S D=3.19$ ) at the time of the first home visit. Children were $60.6 \%$ European American, $10.1 \%$ African American, $11.9 \%$ Latino (predominantly Puerto Rican), and $17.4 \%$ multi-ethnic. Mothers' average age was 33.12 years $(S D=7.01)$ and fathers' average age was $36.52(S D=7.61)$. Mothers averaged 13.89 years of education $(S D=2.69)$ and fathers averaged 13.80 years $(S D=2.81)$. The majority of mothers $(58.7 \%)$ and fathers $(83.5 \%)$ were employed, working an average of $31.68 \mathrm{~h}$ per week $(S D=13.07)$ and $43.35 \mathrm{~h}$ per week $(S D=10.49)$, respectively. The median family income was $\$ 57,000$. The sample in this study did not differ from the 90 families of children with behavior problems not included in this study on child age, child gender, child race, family income, mother's age, or father's age (all $p s>0.05$ ). The sample used in the present study had fathers (13.80 years) and mothers (13.89 years) with more education than the 90 families not included in the study (fathers averaged 12.76 years and mothers averaged 12.94 years of education in the 90 families not included), $t(135.89)=$ $-2.45, p=0.02, t(185)=-2.34, p=0.02$, respectively.

\section{Procedure}

Participants were recruited through state birth records, pediatrician offices, and child care/ community centers throughout western Massachusetts. Children with significant externalizing problems were recruited from 1752 3-year-old children whose parents completed a screening packet containing the Behavior Assessment System for Children Parent Report Scale (BASC-PRS; Reynolds and Kamphaus 1992) and a questionnaire assessing for exclusion criteria, parental concern about externalizing symptoms, and demographic information. Participants had no evidence of intellectual disabilities, deafness, blindness, language delay, cerebral palsy, epilepsy, autism, or psychosis. Inclusion criteria were: (a) parent responded "yes" or "possibly" to: "Are you concerned about your child's activity level, defiance, aggression, or impulse control?" and (b) BASC-PRS hyperactivity and/or aggression subscale $T$ scores fell at or above 65 (1.5 SDs above the mean). Annual assessments were conducted from age 3 to age 6 ; however, the present study focuses on measures that were completed when the children were 3 years old (T1). Each parent was paid $\$ 200$ for their participation at T1. Written informed consent was obtained from all parents who participated. The study was reviewed and approved by the authors' Institutional Review Board. 


\section{Measures}

Parent Psychopathology Symptoms-The Millon Clinical Multiaxial Inventory- III (MCMI-III; Millon et al. 1997), a 175-item questionnaire measuring symptoms from Diagnostic and Statistical Manual of Mental Disorders Axis I and II disorders, was used to measure parental reports of psychopathology symptoms at T1. Standardized Base Rate (BR) scores were used, where BR scores of 75 or higher are considered to be clinically significant (e.g., the number of individuals in the normative clinical sample with a score of 75 or higher corresponded to the percentage of people in the normative clinical sample with that clinical diagnosis). Previous research with this data set (Harvey et al. 2011) identified the following dimensions, which were used in the present study: (a) borderline symptoms ( $a=0.82$ for mothers and 0.84 for fathers); (b) Cluster A symptoms (paranoid, schizoid, and schizotypal; $a=0.92$ for mothers and 0.91 for fathers); (c) Cluster $\mathrm{C}$ symptoms (dependent and avoidant; $\mathrm{a}=0.87$ for mothers and 0.81 for fathers); (d) anxiety symptoms (anxiety disorders, somatoform disorders, and post-traumatic stress disorder; $a=91$ for mothers and 0.92 for fathers); (e) depression symptoms (depressive, dysthymic, and major depressive disorders; $\alpha=0.93$ for mothers and fathers); and (f) substance use ( $\alpha=0.81$ for mothers and 0.88 for fathers). ${ }^{1}$

Audiotaped Assessment of Emotion Socialization-Mothers and fathers were each asked to use a micro-cassette player to record $2 \mathrm{~h}$ of interaction with their children, selecting times of day that tended to be challenging. An earlier review of the tapes suggested that a 30 min segment was sufficient to capture a wide array of behavior representative of the entire 2 $\mathrm{h}$ (Harvey et al. 2011). Parents rated the tapes on how typical the recorded interaction was of their 'usual' parent-child interactions with ratings of 1 (not typical) to 4 (very typical). Mothers' and fathers' interactions averaged between the 'somewhat typical' and 'typical' ratings; $M=2.94, S D=0.83 ; M=2.85, S D=0.69$, respectively.

A coding system was developed to assess emotion socialization practices. The present study focuses on the specific codes that assessed parental responses to child negative affect. The reactions to child negative affect codes included dimensions that have been assessed with existing self-report measures of emotion socialization (e.g., Fabes et al. 1990; Friedlmeier et al. 2011; Raval and Martini 2009) as well as other reactions that were identified after reviewing a random sample of audiotapes. Global frequency ratings of child negative affect were made every 5 min and ranged from 1 (no instances of negative affect) to 7 (very often expresses negative affect). In those 5 min segments in which child negative affect ratings were greater than 1 , the following 14 parent reactions to negative affect codes were also rated on a scale from 1 (does not occur) to 7 (very often occurs): parental distress, punitive, expressive encouragement, emotion-focused, problem-focused, minimizing/discouraging, positive thinking, limit-setting, compromise, gives in, argues, reasoning/clarifying, redirecting, and non-response.

1Harvey et al. (2011) found that narcissistic, histrionic, and compulsive subscales almost always correlated negatively with other subscales, suggesting that within this nonclinical sample, these subscales may actually measure healthy narcissism, flamboyance, and organization, respectively. Thus, these subscales were not included in analyses. 
Twenty undergraduate research assistants served as coders and each tape was rated by two independent coders. Because reactions to negative affect were only coded during intervals in which the child exhibited negative affect (and was coded N/A otherwise), the following procedure was used to ensure that both coders made ratings of reactions to negative affect when negative affect was present. Each tape was first coded independently by two coders using all codes. One of the authors then reviewed the ratings and identified intervals in which one coder gave a rating greater than 1 for negative affect (indicating the presence of negative affect) and the other coder gave a rating of 1 (indicating no negative affect which meant that they rated all reactions to negative affect as N/A). When discrepancies were present, the same two coders listened to the segment(s) where the discrepancy occurred and came to a consensus regarding whether negative affect was present. If they agreed that it was not present, all reactions to negative affect were coded N/A. If they agreed that negative affect was present, the coder who originally did not code for reactions to negative affect independently reviewed the tape again and coded that segment for parent reactions to negative affect. Coders did not discuss nor view each others' ratings of reactions to negative affect during this process.

Ratings were averaged across the rater pairs. Intraclass correlations (ICC) were calculated to determine reliability. Redirection, positive thinking, and argues were dropped due to low reliability; limit setting and giving in reactions were dropped due to low occurrence. In addition to the non-response reaction, six of the remaining eight reactions corresponded directly to the Coping with Children's Negative Emotions Scale subscales (CCNES; Fabes et al. 1990). As the CCNES is the most commonly used self-report measure of emotion socialization, we chose to use these six reactions (distress, punitive, encouraging, emotionfocused, problem-focused, minimizing/discouraging) so that our findings might be more easily compared to other studies using self-report. For data reduction purposes, we aggregated the emotion socialization codes into three variables based on theory: supportive reactions, non-supportive reactions, and non-response reactions. Supportive reactions consisted of an average of encouraging, emotion-focused, and problem-focused reactions. The ICC for the supportive reactions aggregate was 0.73 . The non-supportive reactions aggregate was constructed by averaging distress, punitive, and minimizing/discouraging reactions. The ICC for the non-supportive reactions aggregate was 0.73 . The ICC for nonresponse reactions was 0.68 .

Audiotaped interactions were used to assess emotion socialization because they have several advantages over parent-report and videotaped interactions. First, compared to parent-report, audiotapes provide for a more objective assessment of parenting practices and are less subject to parental bias. Second, compared to videotapes, audiotapes tend to elicit less reactivity (e.g., change in behavior as a result of being observed), something that is crucial given our interest in exploring parental reactions to negative affect. Videotaped interactions were collected as part of the larger study, but there was too little child negative affect during these interactions to warrant coding for reactions to negative affect. The primary disadvantage of audiotaped interactions is that only verbal emotion socialization practices could be assessed; non-verbal behaviors could not be coded. However, although non-verbal emotion socialization is clearly important, much of emotion socialization involves verbal practices; for example, the vast majority of items on one of the most widely used parent- 
report measures of emotion socialization (Fabes et al. 1990) focus on verbal parenting behaviors. In sum, although the use of audiotapes limited our ability to capture non-verbal emotion socialization strategies, this limitation seems to be far outweighed by their advantage in providing a less intrusive and more naturalistic assessment of typical parentchild interactions.

\section{Analytic Plan}

Descriptive statistics, including means, standard deviations, and distributions were first examined. Hierarchical linear modeling (HLM) was used to examine the relation between parent psychopathology symptoms and emotion socialization practices to take into account dependency between mother and father data. A full actor-partner interdependence model was used (Cook and Kenny 2005), which utilizes the two-intercept approach, allowing for estimates of two intercepts, one for each parent. A Level 1 file was constructed including each emotion socialization practice as an outcome variable, and dummy-coded parent variables as predictor variables. The mother parent variable was scored 1 for mothers and 0 for fathers, and the father parent variable was scored 0 for mothers and 1 for fathers. The Level 1 model was as follows: $Y_{p}=\beta_{1 p}(\mathrm{mom})+\beta_{2 p}(\mathrm{dad})+r_{p}$, where $Y$ represents the emotion socialization outcome variable used by person $p$ with residual $r$, mom is a dummy coded variable indicating whether the mother was the one engaging in the outcome variable, and dad is a dummy coded variable indicating whether the father was the one engaging in the outcome variable. In this model, $\beta_{1 \mathrm{p}}$ and $\beta_{2 \mathrm{p}}$ represent the level of emotion socialization practice used, rated for the mother and father, respectively. For the Level 2 models, each parent psychopathology variable as well as an aggregate psychopathology measure was entered into separate models to predict Level 1 emotion socialization practice parameters. For example, for depression, the Level 2 model was:

$$
\begin{array}{llll}
\beta 1 \mathrm{p}= & \gamma 10+\gamma 11 & \text { Mom Depression }+\gamma 12 & \text { Dad Depression }+\mathrm{u} 1 \mathrm{p} \\
\beta 2 \mathrm{p}=\gamma 20+\gamma 21 & \text { Mom Depression }+\gamma 22 & \text { Dad Depression }+\mathrm{u} 2 \mathrm{p}
\end{array}
$$

Level 2 models estimated the relationship between mothers' reactions and mothers' psychopathology $\left(\gamma_{11}\right)$, mothers' reactions and fathers' psychopathology $\left(\gamma_{12}\right)$, fathers' reactions and mothers' psychopathology $\left(\gamma_{21}\right)$, and fathers' reactions and fathers' psychopathology $\left(\gamma_{22}\right)$. When there were missing emotion socialization data for one of the two parents, either because the parent did not complete the audiotapes or because there was no child negative affect, HLM estimated the missing data at Level 1 using the information that was present. Because a number of families were missing emotion socialization data for one of the two parents, analyses were rerun with just the sample of families who had complete data for both parents $(n=68)$ to determine whether results were similar. The differences in results are noted in the footnote of Table 3. Differences should be interpreted in the context of reduced power due to the smaller sample size, resulting in increased standard errors, despite relatively stable coefficients. 


\section{Results \\ Descriptive Statistics}

Intercorrelations among parents' psychopathology symptoms, emotion socialization practices, and child negative affect are presented in Table 1. Medium- to large-sized correlations were observed among psychopathology dimensions for both mothers and fathers. Child negative affect was significantly correlated with mothers' supportive, nonsupportive, and non-response reactions, but not with fathers' reactions. Descriptive statistics for the MCMI-III subscales are presented in Table 2. Mean scores for all psychopathology symptoms were below the clinical range, with $0-23.7 \%$ of mothers and $1.3-30.4 \%$ of fathers falling in the clinical range depending on the disorder.

\section{Differences Between Mothers' and Fathers' Emotion Socialization Practices}

Examining mean differences in mothers' and fathers' emotion socialization practices is useful for interpreting gender-related patterns of relations between parent psychopathology and emotion socialization practices. Therefore, we first compared mothers' and fathers' emotion socialization practices. Because not all children had two parents who completed audiotaped interactions that contained negative affect, independent, rather than paired samples $t$-tests, were used to compare mothers and fathers. Mothers showed greater variability than fathers in their reactions to child negative affect, as measured by the Levene's Test for Equality of Variance for both supportive, $F(1,175)=7.14, p=0.008$, and non-supportive reactions, $F(1,175)=12.38, p=0.001$. Mothers used significantly more supportive $(M=1.20, S D=0.20)$ and non-supportive $(M=1.21, S D=0.24)$ reactions in response to child negative affect than did fathers $(M=1.10, S D=0.15 ; M=1.11, S D=0.17$; respectively), $t(158.19)=3.62, p<0.001$, Cohen's $d=0.57$ and $t(158.50)=3.24, p=0.001$, Cohen's $d=0.48$, respectively. Mothers $(M=1.45, S D=0.47)$ and fathers $(M=1.46, S D=0.47)$ did not differ on not responding to child negative affect, $t(175)=-0.14, p=0.89$, Cohen's $d=0.02$. Children were rated as expressing higher levels of negative affect when interacting with their mothers $(M=1.73, S D=0.65)$ than with their fathers $(M=1.57, S D=0.59)$ at a probability level that approached significance, $t(193)=1.72, p=0.09$, Cohen's $d=0.26$.

\section{Spillover Hypothesis: Are Parent Psychopathology Symptoms Associated With Parents' Own Reactions to Child Negative Emotion?}

The actor effects in the actor-partner model were used to estimate the relation between parent psychopathology symptoms and parental reactions to child negative affect. Results are presented in Table 3.

Mothers-The spillover hypothesis was supported for maternal psychopathology. Specifically, mothers who reported greater anxiety symptoms, substance use, borderline and Cluster A personality symptoms, and greater overall psychopathology symptoms were significantly more likely to use non-supportive reactions to child negative affect. In addition, mothers with greater anxiety and Cluster A personality symptoms were significantly more likely to not respond to child negative affect. 
Fathers-Overall, paternal psychopathology symptoms were not related to their own use of supportive, non-supportive, or non-response reactions to child negative affect. The one exception was that fathers who reported greater borderline personality symptoms were less likely to use supportive reactions to child negative affect.

\section{Crossover and Compensatory Hypotheses: Are Parent Psychopathology Symptoms Associated With Their Partners' Emotion Socialization Practices?}

The partner-effects in the actor partner model were used to estimate the relation between parent psychopathology symptoms and their partners' reactions to child negative affect. Results are presented in Table 3.

Mothers-There was minimal evidence supporting the compensatory hypothesis for maternal psychopathology symptoms. Partners of mothers with more anxiety symptoms were more likely to use supportive reactions to child negative affect. There was some evidence supporting the crossover hypothesis for maternal psychopathology symptoms. Partners of mothers with greater levels of borderline and Cluster A personality symptoms and greater overall psychopathology symptoms were more likely to use non-supportive reactions to child negative affect. Maternal psychopathology symptoms were not related to their partners' use of supportive or non-response reactions to child negative affect.

Fathers-Paternal psychopathology symptoms were not related to partners' use of supportive, non-supportive, or non-response reactions to child negative affect.

\section{Discussion}

This study examined spillover, crossover, and compensatory effects of parent psychopathology symptoms on emotion socialization practices in a sample of mothers and fathers of preschool-aged children with behavior problems. The results of this study support all three hypotheses for mothers and suggest that maternal psychopathology symptoms may play a role in the emotion socialization practices they and their partners use with preschoolers with behavior problems. Specifically, maternal psychopathology symptoms were most consistently associated with their use and their partners' use of non-supportive reactions to child negative affect, and somewhat associated with their use of non-response reactions and their partners' use of supportive reactions. In contrast, fathers' psychopathology was largely not significantly associated with either their own or their partners' emotion socialization practices.

\section{Parent Psychopathology Symptoms and Their Own Reactions to Child Negative Affect}

Consistent with the spillover hypothesis, a variety of maternal psychopathology symptoms were associated with maternal reactions to child negative affect, particularly to nonsupportive reactions. These findings extend previous research linking parental psychopathology with parenting more broadly (e.g., Harvey et al. 2011; Kashdan et al. 2004; Zahn-Waxler et al. 2002), and suggest that maternal psychopathology specifically disrupts parental responses to child negative affect. This may be a result of the significant emotion regulation problems typically experienced by mothers with psychopathology (e.g., Gross 
and Levenson 1997), resulting in vulnerability to the effects of child negative affect on their own emotions, and thus their ability to parent and communicate effectively with their children during episodes of negative affect (Cummings and Davies 1994). Specifically, maternal overall psychopathology symptoms, anxiety symptoms, substance use, and borderline and Cluster A personality symptoms were related to their own use of more nonsupportive reactions to child negative affect and maternal anxiety and Cluster A personality symptoms were related to their own use of more non-response reactions to child negative affect. Although it appears that each of these dimensions were similarly associated with emotion socialization, it is not clear whether the processes underlying these relations are the same across dimensions of psychopathology. Contrary to prediction, maternal Cluster C personality and depression symptoms were not associated with reactions to child negative affect. The finding that depression symptoms do not spillover to parents' reactions to child negative affect is consistent with previous findings of parental depressive symptoms not being significantly related to their own supportive reactions to child negative affect (Nelson et al. 2009), but still is unexpected. Both depression and Cluster $\mathrm{C}$ had relations trending towards significance, suggesting that with greater power, and perhaps a sample with more parents exhibiting clinical levels of psychopathology, a relation may be present.

With the exception of borderline personality symptoms and supportive reactions, paternal psychopathology symptoms were not associated with their own reactions to child negative affect. Four possible explanations for these differential effects of psychopathology on emotion socialization exist. First, since fathers tend to spend less time than mothers with their children (e.g., Herbert et al. 2013; McWayne et al. 2008; Roopnarine 2005), the impact of child negative affect for fathers may be different than for mothers. Child negative affect may be more likely to overwhelm the resources of a mother with psychopathology because they are so actively involved in childcare, and thus are exposed to episodes of negative affect more frequently. In contrast, for a father with psychopathology symptoms, the child negative affect may not feel as overwhelming if he is not as active in the parenting role, and therefore experiences child negative affect less frequently. Second, women have been found to display more emotional responsiveness than men (Lithari et al. 2010), to respond to emotions more efficiently than men (Collignon et al. 2010), and to be more sensitive to less salient displays of emotion ( $\mathrm{Li}$ et al. 2008). Thus, when fathers experience psychopathology, it may impact other aspects of their interactions with their children, but may not interfere with their reactions to their children's emotional expressions. In fact, there is evidence that paternal psychopathology is associated with less engagement in father-child activities, possessiveness, inconsistent discipline, more rejecting and less nurturing parenting, more lax parenting, and more father-child conflict (e.g., Harvey et al. 2011; Bronte-Tinkew et al. 2007; Elgar et al. 2007; Johnson et al. 2006b). Third, our results suggest that children may exhibit more negative affect with mothers than with fathers. This greater negative affect may overwhelm the resources of mothers who are experiencing psychopathology symptoms, whereas fathers with psychopathology may be less likely than mothers to face overwhelming negative affect. Finally, mothers in our sample displayed greater variability than fathers in ratings of their supportive and non-supportive reactions to child negative affect. Reduced variability for fathers might have made it more difficult to find significant results in our sample. 


\section{Parent Psychopathology Symptoms and Partners' Reactions to Child Negative Affect}

Corroborating previous research (Nelson et al. 2009), mothers' psychopathology symptoms were associated with their partners' reactions to child negative affect. These findings are consistent with research suggesting that fathers may adjust their parenting practices when their partner has psychopathology symptoms (e.g., Capaldi et al. 2008; Hops et al. 1987). The findings of this study also extend research that documented partner effects of depression on parental reactions to child negative affect (Nelson et al. 2009), and documents partner effects of a number of other psychopathology dimensions, including anxiety, borderline, substance use, and Cluster A symptoms. The findings are in line with the crossover hypothesis and previous research (e.g., Goodman 2008) showing that parent psychopathology symptoms disrupt partners' parenting practices, but also in line with the compensatory hypothesis showing that partners can serve as a buffer from the deleterious effects of parent psychopathology symptoms. Since mothers typically spend more time with their children (e.g., Herbert et al. 2013; McWayne et al. 2008; Roopnarine 2005) and thus play a large role in their preschoolers' emotional development, it may be that when a mother has psychopathology and is not able to adequately socialize her child's emotions, her partner needs to fill this role, using a mix of supportive and non-supportive reactions. In contrast, fathers' psychopathology symptoms were not related to their partners' emotion socialization practices. It may be that because fathers of preschoolers tend to engage in less childcare than mothers, when fathers are less able to engage in their parenting role, it is less burdensome for mothers to help fill this role. More research is needed to explore these possibilities.

\section{Limitations}

The results of the present study should be interpreted in the context of several limitations. First, parents in this study were not clinically diagnosed, and all psychopathology measures were based on parents' self-reports. Although using dimensional measures provides a number of advantages, these findings may not generalize to parents with clinical diagnoses. Further, it is possible that more significant findings would have emerged if our sample had a larger number of parents with clinically significant symptoms. Second, the self-report measure of parent psychopathology was normed on a clinical sample, so the norms may be different for a community sample. Because this study focused on relative symptoms rather than using clinical cutoffs, this should not have substantial bearing on the main findings of this study, but does limit our ability to evaluate the generalizability of these findings. Third, the cross-sectional nature of this study limits causal conclusions. Although our findings were consistent with spillover and crossover hypotheses, they cannot confirm these causal hypotheses. For example, the observed associations between maternal psychopathology and emotion socialization practices could be accounted for by a third variable such as child negative affect; maternal psychopathology may have led to children's greater negative affect which in turn tended to elicit more unsupportive emotion socialization practices. Fourth, there are likely individual differences in the impact of psychopathology symptoms on emotion socialization practices. Further research is needed to explore possible moderators of this relation, including an examination of the interaction among different dimensions of psychopathology. Fifth, the sample for this study was limited to two-parent heterosexual families; thus, the results may not generalize to single-parent or same-sex families. Finally, a 
relatively large number of analyses were conducted so it is possible that some of the findings represent Type I error, pointing to the importance of replicating this study.

\section{Future Directions and Implications}

Despite these limitations, the present study highlights the potential impact of parent psychopathology symptoms on responses to negative affect in preschoolers with behavior problems. This study advances existing research on parent psychopathology symptoms and emotion socialization by examining several types of psychopathology symptoms and by examining parent emotion socialization using observational data and with at-risk children. Critical next steps include identifying the mechanisms underlying the relation between psychopathology symptoms and non-supportive reactions to child negative affect.

Given the central role of parental socialization of emotions for the development of children's emotion regulation, these findings have important clinical implications. The effects of parent psychopathology symptoms on parenting have been well documented (see Zahn-Waxler et al. 2002, for a review), and the current study suggests that these effects are also evident for emotion socialization practices specifically. Considering the extensive literature documenting the importance of parental emotional socialization for children's emotion regulation, the present study suggests that emotion socialization could play an important role in the intergenerational transmission of psychopathology. Finally, the results of the present study suggest that addressing other dimensions of psychopathology beyond depression may be critical in fostering positive emotion socialization and in turn, improving child wellbeing.

\section{Acknowledgments}

This research was supported by a grant from the National Institutes of Health (MH60132) awarded to the second author. The authors wish to thank our wonderful team of undergraduate research assistants, especially Jenna Axelrod, for their hard work on coding the emotion socialization data.

\section{References}

Achenbach TM, Edelbrock CS. The classification of child psychopathology: a review and analysis of empirical efforts. Psychological Bulletin. 1978; 85:1275-1301. doi:10.1037/0033-2909.85.6.1275. [PubMed: 366649]

Achenbach TM, Conners CK, Quay HC, Verhulst FC, Howell CT. Replication of empirically derived syndromes as a basis for taxonomy of child/adolescent psychopathology. Journal of Abnormal Child Psychology. 1989; 17:299-323. doi:10.1007/BF00917401. [PubMed: 2754115]

Barlow DH. Unraveling the mysteries of anxiety and its disorders from the perspective of emotion theory. American Psychologist. 2000; 55:1247-1263. doi:10.1037/0003066X.55.11.1247. [PubMed: 11280938]

Belsky J. The determinants of parenting: a process model. Child Development. 1984; 55:8396. doi: $10.2307 / 1129836$.

Bronte-Tinkew J, Moore KA, Matthews G, Carrano J. Symptoms of major depression in a sample of fathers of infants: sociodemographic correlates and links to father involvement. Journal of Family Issues. 2007; 28:61-99. doi:10.1177/0192513X06293609.

Campbell SB. Hard-to-manage preschool boys: externalizing behavior, social competence, and family context at two-year followup. Journal of Abnormal Child Psychology. 1994; 22:147-166. doi: 10.1007=BF02167897. [PubMed: 8064027] 
Capaldi DM, Pears KC, Kerr DCR, Owen LD. Intergenerational and partner influences on fathers' negative discipline. Journal of Abnormal Child Psychology. 2008; 36:347-350. doi:10.1007/ S10802-007-9182-8. [PubMed: 17899359]

Caspi A, Houts RM, Belsky DW, Goldman-Mellor SJ, Harrington H, Israel S, Moffitt TE. The p factor one general psychopathology factor in the structure of psychiatric disorders? Clinical Psychological Science. 2014; 2:119-137. doi:10.1177/2167702613497473. [PubMed: 25360393]

Chilcoat H, Breslau N, Anthony JC. Impact of parent monitoring on initiation of drug use through late childhood. Journal of the American Academy of Child and Adolescent Psychiatry. 1996; 35:91100. doi:10.1097/00004583-199601000-00017. [PubMed: 8567618]

Cole PM, Michel MK, Teti LO. The development of emotion regulation and dysregulation: a clinical perspective. Monographs of the Society for Research in Child Development. 1994; 59:73-100. doi: 10.2307/1166139. [PubMed: 7984169]

Cole PM, Dennis TA, Smith-Simon KE, Cohen LH. Preschoolers' emotion regulation strategy understanding: relations with emotion socialization and child self-regulation. Social Development. 2009; 18:324-352. doi:10.1111/j.1467-9507.2008.00503.x.

Collignon O, Girard S, Gosselin F, Saint-Amour D, Lepore F, Lassonde M. Women process multisensory emotion expressions more efficiently than men. Neuropsychologia. 2010; 48:220225. doi:10.1016/j.neuropsychologia.2009.09.007. [PubMed: 19761782]

Cook WL, Kenny DA. The actor-partner interdependence model: a model of bidirectional effects in developmental studies. International Journal of Behavioral Development. 2005; 29:101-109. doi: $10.1080 / 01650250444000405$.

Crouter AC, Bumpus MF, Head MR, McHale SM. Implications of overwork and overload for the quality of men's marriages. Journal of Marriage and the Family. 2001; 63:404-417. doi:10.1111/j. 1741-3737.2001.00404.x.

Cummings EM, Davies PT. Maternal depression and child development. Journal of Child Psychology and Psychiatry. 1994; 35:73-112. doi:10.1111/j.1469-7610.1994.tb01133.x. [PubMed: 8163630]

Das Eiden R, Leonard KE. Paternal alcoholism, parental psychopathology, and aggravation with infants. Journal of Substance Abuse. 2000; 11:17-29. doi:10.1016/S08993289(99)00016-4. [PubMed: 10756511]

Denham, S. Emotional development in young children. The Guilford Press; New York: 1998.

Denham S, Kochanoff AT. Parental contributions to pre-schoolers' understanding of emotion. Marriage \& Family Review. 2002; 34:311-343. doi:10.1300/J002v34n03_06.

Denham SA, Workman E, Cole PM, Weissbrod C, Kendziora KT, Zahn-Waxler C. Prediction of externalizing behavior problems from early to middle childhood: the role of parental socialization and emotion expression. Development and Psychopathology. 2000; 12:23-45. doi:10.1017/ S0954579400001024. [PubMed: 10774594]

Denham, SA.; Bassett, HH.; Wyatt, T. The socialization of emotional competence.. In: Grusec, J.; Hastings, P., editors. Handbook of socialization: Theory and research. Guilford Press; New York: 2007. p. 614-637.

Dix T, Meunier LN. Depressive symptoms and parenting competence: an analysis of 13 regulatory processes. Developmental Review. 2009; 29:45-68. doi:10.1016/j.dr.2008.11.002.

DuPaul GJ, McGoey KE, Eckert TL, VanBrakle J. Preschool children with attention-deficit/ hyperactivity disorder: impairments in behavioral, social, and school functioning. Journal of the American Academy of Child and Adolescent Psychiatry. 2001; 40:508-515. doi: 10.1097/00004583-200105000-00009. [PubMed: 11349694]

Edwards EP, Homish GG, Eiden RD, Grohman KK, Leonard KE. Longitudinal prediction of early childhood discipline styles among heavy drinking parents. Addictive Behaviors. 2009; 34:100 106. doi:10.1016/J.Addbeh.2008.08.006. [PubMed: 18818023]

Eiden RD, Edwards EP, Leonard KE. A conceptual model for the development of externalizing behavior problems among kindergarten children of alcoholic families: role of parenting and children's self-regulation. Developmental Psychology. 2007; 43:11871201. doi: 10.1037/0012-1649.43.5.1187.

Eisenberg N, Cumberland A, Spinrad TL. Parental socialization of emotion. Psychological Inquiry. 1998; 9:241-273. doi:10.1207/s15327965pli0904_1. [PubMed: 16865170] 
Elgar FJ, Mills RSL, Mcgrath PJ, Waschbusch DA, Brownridge DA. Maternal and paternal depressive symptoms and child maladjustment: the mediating role of parental behavior. Journal of Abnormal Child Psychology. 2007; 35:943-955. doi:10.1007/S10802-007-9145-0. [PubMed: 17577659]

Fabes, RA.; Eisenberg, N.; Bernzweig, J. The coping with children's negative emotions scale: Procedures and scoring. Available from authors. Arizona State University; Tempe: 1990.

Friedlmeier W, Corapci F, Cole PM. Emotion socialization in cross-cultural perspective. Social and Personality Psychology Compass. 2011; 5:410-427. doi:10.1111/j.1751-9004.2011.00362.x.

Goodman JH. Influences of maternal postpartum depression on fathers and their father-infant interaction. Infant Mental Health Journal. 2008; 29:624-643. doi:10.1002/Imhj.20199.

Gross JJ, Levenson RW. Hiding feelings: the acute effects of inhibiting positive and negative emotions. Journal of Abnormal Psychology. 1997; 106:95-103. doi:10.1037/0021-843X.106.1.95. [PubMed: 9103721]

Harvey EA, Youngwirth SD, Thakar DA, Errazuriz PA. Predicting attention deficit/hyperactivity disorder and oppositional defiant disorder from preschool diagnostic assessments. Journal of Consulting and Clinical Psychology. 2009; 2:349-354. doi:10.1037/a0014638. [PubMed: 19309194]

Harvey E, Stoessel B, Herbert S. Psychopathology and parenting practices of parents of preschool children with behavior problems. Parenting: Science and Practice. 2011; 11:239-263. doi: 10.1080/15295192.2011.613722.

Herbert SD, Harvey EA, Lugo-Candelas CI, Breaux RP. Early fathering as a predictor of later psychosocial functioning among preschool children with behavior problems. Journal of Abnormal Child Psychology. 2013; 41:691-703. doi:10.1007/s10802-012-9706-8. [PubMed: 23269560]

Hersh MA, Hussong AM. The association between observed parental emotion socialization and adolescent self-medication. Journal of Abnormal Child Psychology. 2009; 37:493-506. doi: 10.1007/s10802-008-9291-z. [PubMed: 19137423]

Hops H, Biglan A, Sherman L, Arthur J, Friedman L, Osteen V. Home observations of family interactions of depressed women. Journal of Consulting and Clinical Psychology. 1987; 55:341346. doi:10.1037/0022-006X.55.3.341. [PubMed: 3597946]

Hussong AM, Bauer DJ, Huang W, Chassin L, Sher KJ, Zucker RA. Characterizing the life stressors of children of alcoholic parents. Journal of Family Psychology. 2008; 22:819-832. doi:10.1037/ a0013704. [PubMed: 19102603]

Jacob T, Johnson SL. Parent-child interaction among depressed fathers and mothers: impact on child functioning. Journal of Family Psychology. 1997; 11:391-409. doi:10.1037/0893-3200.11.4.391.

Johnson JG, Cohen P, Kasen S, Brook JS. Paternal psychiatric symptoms and maladaptive paternal behavior in the home during the child rearing years. Journal of Child and Family Studies. 2004; 13:421-437. doi:10.1023/B:JCFS.0000044725.76533.66.

Johnson JG, Cohen P, Kasen S, Brook JS. Maternal psychiatric disorders, parenting, and maternal behavior in the home during the child rearing years. Journal of Child and Family Studies. 2006a; 15:97-114. doi:10.1007/S10826-005-9003-Z.

Johnson JG, Cohen P, Kasen S, Ehrensaft MK, Crawford TN. Associations of parental personality disorders and axis I disorders with childrearing behavior. Psychiatry Interpersonal and Biological Processes. 2006b; 69:336-350. doi:10.1521/psyc.2006.69.4.336.

Kashdan TB, Jacob RG, Pelham WE, Lang AR, Hoza B, Blumenthal JD, Gnagy EM. Depression and anxiety in parents of children with ADHD and varying levels of oppositional defiant behaviors: modeling relationships with family functioning. Journal of Clinical Child and Adolescent Psychology. 2004; 33:169-181. doi:10.1207/S15374424JCCP3301_16. [PubMed: 15028551]

Kessler RC, Chiu WT, Demler O, Walters EE. Prevalence, severity, and comorbidity of 12-month DSM-IV disorders in the National Comorbidity Survey Replication. Archives of general psychiatry. 2005; 62:617-627. doi:10.1001/archpsyc.62.6.617. [PubMed: 15939839]

Kring, AM.; Werner, KH. Emotion regulation and psycho-pathology.. In: Philippot, P.; Feldman, RS., editors. The regulation of emotion. Lawrence Erlbaum Associates, Inc.; Mahwah: 2004. p. 359-385. 
Krueger RF, Markon KE. Reinterpreting comorbidity: a model-based approach to understanding and classifying psychopathology. Annual Review of Clinical Psychology. 2006; 2:111-133. doi: 10.1146/annurev.clinpsy.2.022305.095213.

Lahey BB, Applegate B, Hakes JK, Zald DH, Hariri AR, Rathouz PJ. Is there a general factor of prevalent psycho-pathology during adulthood? Journal of Abnormal Psychology. 2012; 121:971977. doi:10.1037/a0028355. [PubMed: 22845652]

Li H, Yuan J, Lin C. The neural mechanism underlying the female advantage in identifying negative emotions: an event-related potential study. NeuroImage. 2008; 40:19211929. doi:10.1016/ j.neuroimage.2008.01.033.

Lithari C, Frantzidis CA, Papadelis C, Vivas AB, Klados MA, Kourtidou-Papadeli C, Bamidis PD. Are females more responsive to emotional stimuli? A neurophysiological study across arousal and valence dimensions. Brain Topography. 2010; 23:27-40. doi:10.1007/s10548-009-0130-5. [PubMed: 20043199]

Lovejoy MC, Graczyk PA, O'Hare E, Neuman G. Maternal depression and parenting behavior: a metaanalytic review. Clinical Psychology Review. 2000; 20:561-592. doi:10.1016/ S0272-7358(98)00100-7. [PubMed: 10860167]

Markon KE. Modeling psychopathology structure: a symptom-level analysis of Axis I and II disorders. Psychological Medicine. 2010; 40:273-288. doi:10.1017/S0033291709990183. [PubMed: 19515267]

McElwain LN, Halberstadt AG, Volling BL. Mother-and father-reported reactions to children's negative emotions: relations to young children's emotional understanding and friendship quality. Child Development. 2007; 78:1407-1425. doi:10.1111/j.1467-8624.2007.01074.x. [PubMed: 17883439]

McWayne C, Campos R, Owsianik M. A multidimensional, multilevel examination of mother and father involvement among culturally diverse head start families. Journal of School Psychology. 2008; 46:551-573. doi:10.1016/j.jsp.2008.06.001. [PubMed: 19083372]

Michalik NM, Eisenberg N, Spinrad TL, Ladd B, Thompson M, Valiente C. Longitudinal relations among parental emotional expressivity and sympathy and prosocial behavior in adolescence. Social Development. 2007; 16:286-309. doi:10.1111/j.1467-9507.2007.00385.x. [PubMed: 17710212]

Middleton M, Scott SL, Renk K. Parental depression, parenting behaviours, and behaviour problems in young children. Infant and Child Development. 2009; 18:323-336. doi:10.1002/icd.598.

Millon, T.; Davis, RD.; Millon, C. MCMI-III Manual. National Computer Systems; 1997.

Mokrova I, O'Brien M, Calkins S, Keane S. Parental ADHD symptomology and ineffective parenting: the connecting link of home chaos. Parenting Science and Practice. 2010; 10:119-135. doi: 10.1080/15295190903212844.

Morris AS, Silk JS, Steinberg L, Myers SS, Robinson LR. The role of the family context in the development of emotion regulation. Social Development. 2007; 16:361388. doi:10.1111/j. 1467-9507.2007.00389.x.

Nelson JA, O'Brien M, Blankson AN, Calkins SD, Keane SP. Family stress and parental responses to children's negative emotions: tests of the spillover, crossover, and compensatory hypotheses. Journal of Family Psychology. 2009; 23:671-679. doi:10.1037/a0015977. [PubMed: 19803603]

Newman DL, Moffitt TE, Caspi A, Silva PA. Comorbid mental disorders: implications for treatment and sample selection. Journal of Abnormal Psychology. 1998; 107:305-311. doi: 10.1037/0021-843X.107.2.305. [PubMed: 9604559]

Pfiffner LJ, McBurnett K, Rathouz PJ, Judice S. Family correlates of oppositional and conduct disorders in children with attention deficit/hyperactivity disorder. Journal of Abnormal Child Psychology. 2005; 33:551-563. doi:10.1007/s10802005-6737-4. [PubMed: 16195950]

Raval VV, Martini TS. Maternal socialization of children's anger, sadness, and physical pain in two communities in Gujarat, India. International Journal of Behavioral Development. 2009; 33:215229. doi:10.1177/0165025408098022.

Reynolds, CR.; Kamphaus, RW. Behavior assessment system for children: Manual. American Guidance Service; Circle Pines: 1992. 
Riordan D, Appleby L, Faragher B. Mother-infant interaction in post-partum women with schizophrenia and affective disorders. Psychological Medicine. 1999; 29:991-995. doi:10.1017/ S0033291798007727. [PubMed: 10473327]

Roberts NA, Levenson RW. The remains of the workday: impact of job stress and exhaustion on marital interaction in police couples. Journal of Marriage and the Family. 2001; 63:1052-1067. doi:10.1111/j.1741-3737.2001.01052.x.

Roopnarine JL. Mothers' and fathers' behaviors toward their 3-to 4-month-old infants in lower, middle, and upper socioeconomic African-American families. Developmental Psychology. 2005; 41:723-732. doi:10.1037/0012-1649.41.5.723. [PubMed: 16173870]

Takeda T, Stotesbery K, Power T, Ambrosini PJ, Berrettini W, Hakonarson H, Elia J. Parental ADHD status and its association with proband ADHD subtype and severity. Journal of Pediatrics. 2010; 157:995-1000. doi:10.1016/j.jpeds.2010.05.053. [PubMed: 20630538]

Valiente C, Lemery-Chalfant K, Reiser M. Pathways to problem behaviors: chaotic homes, parent and child effortful control, and parenting. Social Development. 2007; 16:249-267. doi:10.1111/j. 1467-9507.2007.00383.x.

Warren HK, Stifter CA. Maternal emotion-related socialization and preschoolers' developing emotion self-awareness. Social Development. 2008; 17:239-256. doi:10.1111/j.1467-9507.2007.00423. x.

Westman M. Stress and strain crossover. Human Relations. 2001; 54:717-751. doi: $10.1177 / 0018726701546002$.

Whaley SE, Pinto A, Sigman M. Characterizing interactions between anxious mothers and their children. Journal of Consulting and Clinical Psychology. 1999; 67:826-836. doi: 10.1037/0022-006X.67.6.826. [PubMed: 10596505]

Woodruff-Borden J, Morrow C, Bourland S, Cambron S. The behavior of anxious parents: examining mechanisms of transmission of anxiety from parent to child. Journal of Clinical Child and Adolescent Psychology. 2002; 31:364-374. doi:10.1207/S15374424JCCP3103_08. [PubMed: 12149974]

Zahn-Waxler, C.; Duggal, S.; Gruber, R. Parent psychopathology.. In: Bornstein, MH., editor. Handbook of parenting. 2nd ed.. Vol. 3. Lawrence Erlbaum Associates; Mahwah: 2002. p. 295-327. 


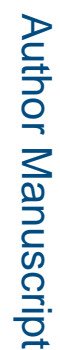

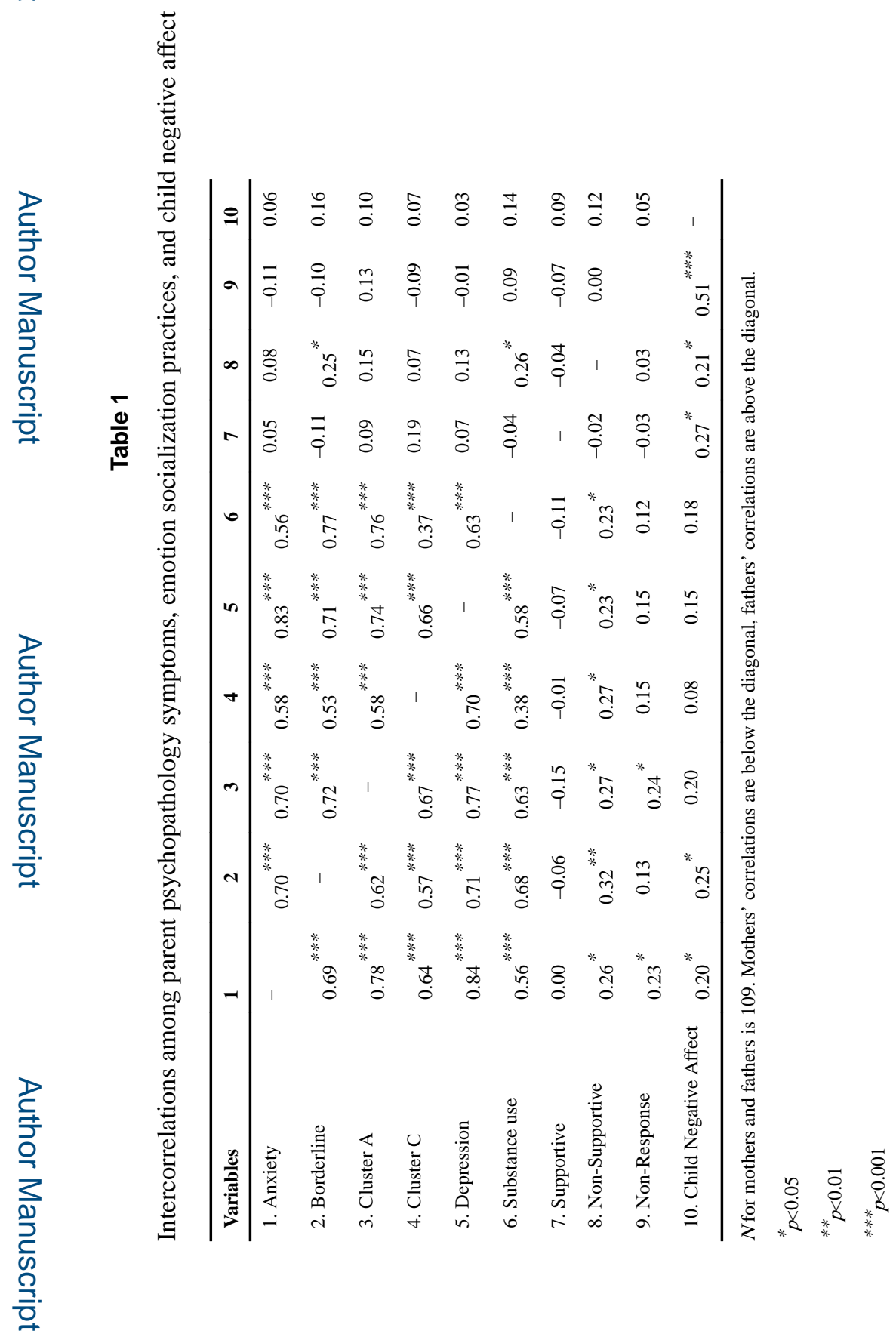


Table 2

Descriptive statistics for MCMI-III subscales

\begin{tabular}{|c|c|c|c|c|}
\hline \multirow[t]{2}{*}{ Variable } & \multicolumn{2}{|l|}{ Mother } & \multicolumn{2}{|l|}{ Father } \\
\hline & $M(S D)$ & $\% \mathrm{BR} \geq 75^{a}$ & $M(S D)$ & $\% \mathrm{BR} \geq 75^{a}$ \\
\hline \multicolumn{5}{|l|}{ Cluster A } \\
\hline Schizoid & $43.24(22.08)$ & 11.3 & $52.33(25.45)$ & 25.3 \\
\hline Schizotypal & $30.75(25.24)$ & 3.1 & 33.34 (26.47) & 1.3 \\
\hline Paranoid & $40.71(28.79)$ & 12.4 & $39.43(27.21)$ & 7.6 \\
\hline Borderline & $30.31(24.62)$ & 8.2 & $28.80(23.90)$ & 7.6 \\
\hline \multicolumn{5}{|l|}{ Cluster C } \\
\hline Avoidant & $40.04(22.45)$ & 10.3 & $44.99(26.82)$ & 22.8 \\
\hline Dependent & $46.52(22.62)$ & 13.4 & $50.96(22.88)$ & 20.3 \\
\hline \multicolumn{5}{|l|}{ Anxiety } \\
\hline Anxiety & $38.34(28.80)$ & 23.7 & $39.41(32.07)$ & 26.6 \\
\hline Somatoform & $26.40(21.14)$ & 2.1 & 33.29 (28.17) & 3.8 \\
\hline PTSD & $29.13(24.55)$ & 5.2 & $28.29(21.27)$ & 3.8 \\
\hline \multicolumn{5}{|l|}{ Depression } \\
\hline Major depression & $25.54(22.62)$ & 5.2 & $27.95(25.70)$ & 3.8 \\
\hline Dysthymia & $20.52(19.23)$ & 6.2 & $30.43(26.56)$ & 10.1 \\
\hline Depressive & $37.94(25.15)$ & 13.4 & $47.77(29.32)$ & 30.4 \\
\hline \multicolumn{5}{|l|}{ Personality } \\
\hline \multicolumn{5}{|l|}{ Substance abuse } \\
\hline Alcohol & $46.65(30.04)$ & 12.4 & $42.01(28.55)$ & 16.5 \\
\hline Drug & $38.35(25.22)$ & 0.0 & $33.85(22.08)$ & 3.8 \\
\hline
\end{tabular}

${ }^{a}$ Indicates the percentage of parents who had psychopathology Base Rate scores of at least 75 , representing clinically significant symptomatology 


\section{Table 3}

Relation between parent psychopathology and parental reactions to child negative affect

\begin{tabular}{|c|c|c|c|c|c|c|}
\hline \multirow[t]{2}{*}{ Parent psychopathology } & \multicolumn{3}{|c|}{ Mother's emotion socialization practices } & \multicolumn{3}{|c|}{ Father's emotion socialization practices } \\
\hline & $\begin{array}{r}\text { Supportive } \\
\text { reactions } \gamma \\
(S E)\end{array}$ & $\begin{array}{l}\text { Non-supportive } \\
\text { reactions } \gamma(S E)\end{array}$ & Non-response $\gamma(S E)$ & $\begin{array}{c}\text { Supportive } \\
\text { reactions } \gamma(\boldsymbol{S E})\end{array}$ & $\begin{array}{l}\text { Non-supportive } \\
\text { reactions } \gamma(S E)\end{array}$ & Non-response $\gamma(S E)$ \\
\hline \multicolumn{7}{|l|}{ Maternal } \\
\hline Anxiety & $0.003(0.020)$ & $0.067(0.032)^{a^{*}}$ & $0.136(0.058){ }^{*}$ & $0.055(0.027)^{d *}$ & $0.035(0.023)$ & $0.023(0.052)$ \\
\hline Borderline & $-0.019(0.018)$ & $0.081(0.030)^{* *}$ & $0.066(0.063)$ & $0.045(0.027)^{* * *}$ & $0.030(0.015)^{*}$ & $0.066(0.058)$ \\
\hline Cluster A & $-0.043(0.026)$ & $0.080(0.034)^{*}$ & $0.139(0.069)^{c^{*}}$ & $0.044(0.031)$ & $0.051(0.024)^{g *}$ & $-0.022(0.069)$ \\
\hline Cluster C & $0.004(0.022)$ & $0.068(0.038)^{\text {**** }}$ & $0.066(0.063)$ & $0.030(0.023)$ & $0.038(0.023)$ & $0.064(0.059)$ \\
\hline Depression & $-0.017(0.017)$ & $0.051(0.037)$ & $0.095(0.057)^{* * *}$ & $0.033(0.029)$ & $0.036(0.024)$ & $0.023(0.061)$ \\
\hline Substance & $-0.030(0.027)$ & $0.065(0.032)^{*}$ & $0.074(0.063)$ & $0.041(0.027)$ & $0.043(0.023)^{* * * *}$ & $-0.049(0.051)$ \\
\hline Psychopathology Aggregate & $-0.024(0.026)$ & $0.100(0.041)^{b^{*}}$ & $0.131(0.073)^{* * *}$ & $0.059(0.036)^{* * *}$ & $0.052(0.025)^{h^{*}}$ & $0.026(0.074)$ \\
\hline \multicolumn{7}{|l|}{ Paternal } \\
\hline Anxiety & $-0.014(0.025)$ & $0.008(0.032)$ & $-0.035(0.060)$ & $-0.007(0.018)$ & $0.005(0.025)$ & $-0.068(0.060)$ \\
\hline Borderline & $0.017(0.022)$ & $-0.005(0.028)$ & $0.081(0.062)$ & $-0.029(0.014) e^{e^{*}}$ & $0.035(0.020)^{\mathrm{t}}$ & $-0.062(0.054)$ \\
\hline Cluster A & $0.017(0.026)$ & $-0.011(0.030)$ & $-0.022(0.066)$ & $0.003(0.016)$ & $0.014(0.026)$ & $0.082(0.059)$ \\
\hline Cluster C & $-0.026(0.024)$ & $0.017(0.035)$ & $0.081(0.062)$ & $0.028(0.020)$ & $0.008(0.023)$ & $-0.062(0.054)$ \\
\hline Depression & $0.004(0.024)$ & $0.017(0.034)$ & $-0.035(0.065)$ & $-0.001(0.029)$ & $0.011(0.021)$ & $-0.011(0.067)$ \\
\hline Substance & $0.012(0.025)$ & $-0.012(0.029)$ & $-0.033(0.061)$ & $-0.021(0.016)^{f}$ & $0.033(0.023)$ & $0.067(0.056)$ \\
\hline Psychopathology Aggregate & $0.005(0.030)$ & $-0.009(0.039)$ & $-0.013(0.076)$ & $-0.012(0.100)$ & $0.026(0.030)$ & $-0.007(0.065)$ \\
\hline
\end{tabular}

For the smaller sample of families in which reactions to negative affect were coded for both parents, the relationships that changed are denoted with the following superscripts:

$a_{\text {relation was no longer significant }(b=0.06, S E=0.09, p=0.49)}$

$b_{\text {relation became a trend, }(b=0.09, S E=0.05, p=0.06)}$

$c_{\text {relation was no longer significant }(b=0.11, S E=0.07, p=0.11)}$

$d_{\text {relation was no longer significant }(b=0.03, S E=0.02, p=0.17)}$

$e_{\text {relation became a trend }(b=-0.03, S E=0.02, p=0.07)}$

$f_{\text {relation became significant for the smaller sample }(b=0.05, S E=0.02, p=0.02)}$

$\left.g_{\text {relation was no longer significant }(~} b=0.04, S E=0.02, p=0.11\right)$

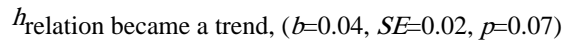

* $p<0.05$

*** $\mathrm{p}<01$

**** $p<0.10$ 